\title{
The Lovén reflex: the renaissance of a long-forgotten reflex involving autonomic and nociceptive pathways
}

\author{
Wilfrid Jänig ${ }^{1}$
}

Received: 7 December 2020 / Accepted: 8 December 2020 / Published online: 29 January 2021

(c) Springer-Verlag GmbH Germany, part of Springer Nature 2021

Keywords Vasoconstrictor neurons $\cdot$ Nociceptive afferents $\cdot$ Nociceptive reflexes $\cdot$ Muscle $\cdot$ Skin

\section{Introduction}

The Swedish physiologist Otto Christian Lovén (1835-1904), while working in Carl Ludwig's laboratory in Leipzig, described in rabbits an inhibitory reflex in skin generated by noxious stimulation of the skin and mediated by cutaneous vasoconstrictor neurons [16]. Lovén found that electrical stimulation of the central stump of the dorsal nerve of the hind paw, a branch of the superficial peroneal nerve (the nervus dorsalis pedis, a skin nerve), results in (1) ipsilateral saphenous artery vasodilatation; (2) no vasodilation but sometimes vasoconstriction in the ear lobe; and, (3) systemic vasoconstriction causing an increase in blood pressure. Conversely, stimulation of the central stump of the posterior branch of the auricular nerve results in (1) vasodilation in the ipsilateral ear lobe; (2) no vasodilation but sometimes vasoconstriction of the saphenous artery; and, (3) systemic vasoconstriction causing an increase in blood pressure. Lovén concluded that vasomotor fibers innervating the saphenous artery or ear blood vessels must be different from the vasomotor fibers responsible for the increase in systemic blood pressure and that vasodilation of skin vessels is generated reflexly by stimulation of afferents which innervate the same skin territory that is innervated by the cutaneous vasomotor fibers or a close-by territory. Lovén did not comment on his results as being generated by decreased activity in vasoconstrictor neurons or activation of vasodilator neurons; the details of the concept of nerve-mediated vasoconstriction and vasodilation developed much later. Lovén's observation went into the literature as the "Lovén reflex."

Wilfrid Jänig

w.janig@physiologie.uni-kiel.de

1 Institute of Physiology, Christian-Albrechts-Universität zu Kiel, Olshausenstr. 40, 24098 Kiel, Germany
Bayliss [2] reproduced the Lovén reflex indirectly for skeletal muscle in dogs by using plethysmography to measure the volume change of the hindlimb, which is largely dependent on blood flow through the skeletal muscle. Electrical stimulation of the distally cut lumbar dorsal root L6 elicited vasodilation in the hindlimb, whereas electrical stimulation of the median nerve elicited vasoconstriction in the hindlimb. Bayliss and other authors of textbook chapters describing the Lovén reflex $[1,3,5,6]$ believed that the reflex vasodilation resulting from stimulation of likely nociceptive afferents innervating the same tissues as the efferent sympathetic fibers is likely to be a general phenomenon everywhere in the body. Thus, Lovén's results were generalized to organs other than the skin, although Lovén never investigated the reflex inhibition in other organs. The Lovén reflex was described in Anglo-American but not in German textbooks. It has been forgotten since the 1950s.

\section{Neurophysiological studies in animals}

The Lovén reflex in cutaneous vasoconstrictor (CVC) neurons was rediscovered in my laboratories in Heidelberg [7] and in Kiel $[9,10]$ and extended to muscle vasoconstrictor (MVC) neurons [15]. The activity was recorded from postganglionic CVC or MVC axons innervating the hind limb in anesthetized cats or rats in vivo. Nociceptive afferent neurons in the skin were stimulated mechanically or in skeletal muscle by application of hypertonic saline (Fig. 1). Noxious stimulation of the hind paw skin leads to inhibition of the activity in most CVC neurons innervating the same hind paw, but not to inhibition (or even to weak excitation) of most CVC neurons innervating the contralateral hind paw. Most MVC neurons innervating the ipsilateral or contralateral hindlimb are not affected or weakly excited by these cutaneous stimuli. Noxious stimulation of skeletal muscle 
Fig. 1 A hypothesis on the organization of the inhibitory nociceptive reflexes in the cutaneous vasoconstrictor (CVC) system and the muscle vasoconstrictor (MVC) system. Stimulation of cutaneous nociceptive afferent neurons leads to inhibition of ipsilaterally projecting CVC neurons but not of MVC neurons. Stimulation of muscle nociceptive afferent neurons leads to inhibition of ipsilaterally projecting MVC neurons but not of CVC neurons. The inhibitory reflexes are organized at the level of the spinal cord. The inhibitory interneurons (indicated by $\Theta$ ) are possibly located in the same spinal segments as the preganglionic vasoconstrictor neurons. The spinal nociceptive inhibitory reflex pathways are largely, but not entirely, lateralized. It is hypothesized that they are under differential supraspinal control. $B V$ blood vessel, $D R G$ dorsal root ganglion, $L$ lumbar, symp ggl sympathetic ganglion. Modified from [15]

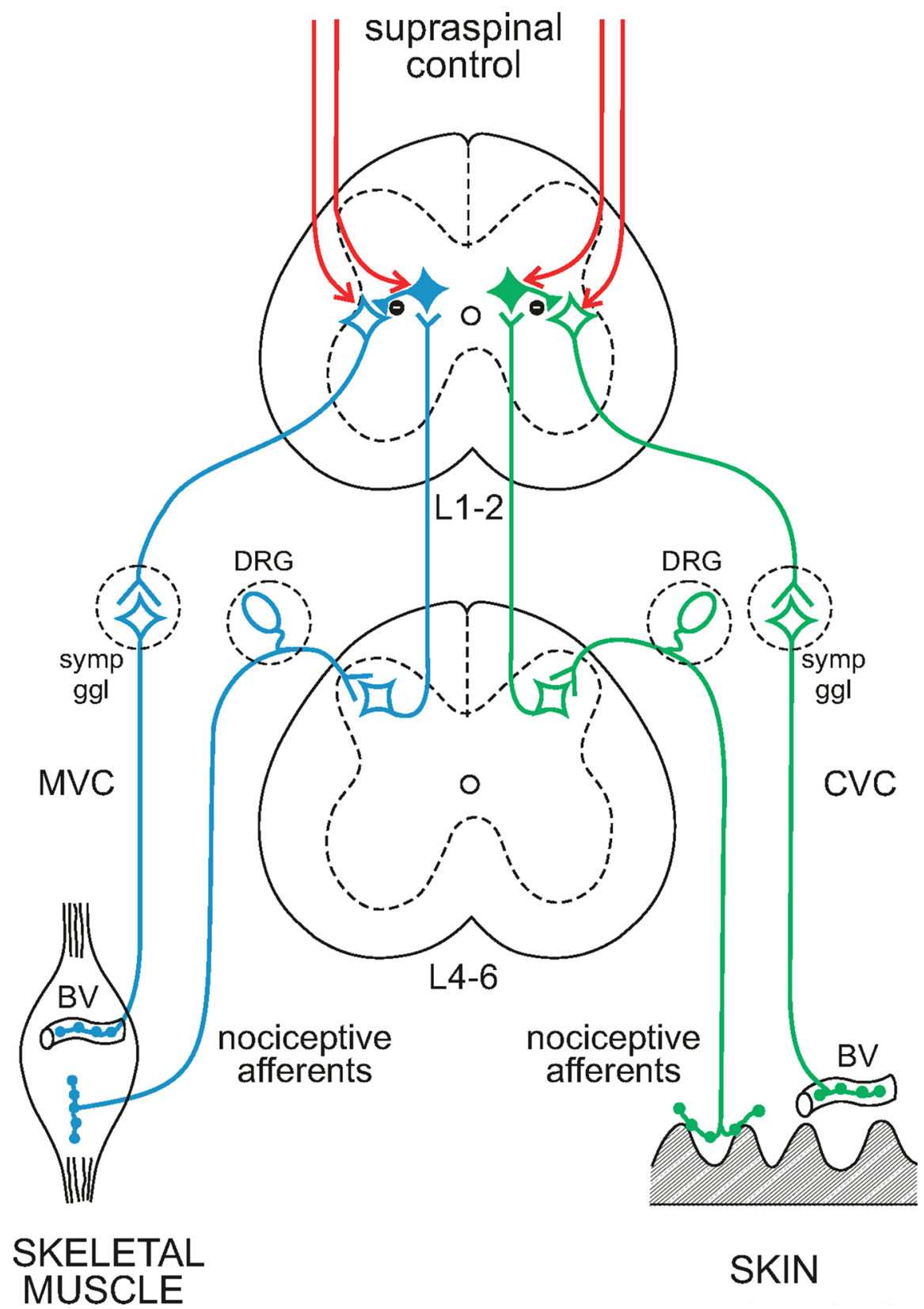

leads to strong inhibition of activity in most MVC neurons of the same extremity; CVC neurons are not inhibited by these noxious muscle stimuli but, in contrast, are excited (Fig. 1). These functionally distinct inhibitory nociceptive reflexes in vasoconstrictor neurons demonstrate the close integration between nociceptive and vasoconstrictor systems at the spinal cord level.

The pathways of the nociceptive inhibitory reflexes are most likely spinal. This has been tested for CVC neurons on cats with chronic spinal cord transections $[8,13]$. The inhibitory nociceptive reflexes take time to recover after spinal cord transection because of the spinal shock due to the interruption of descending supraspinal systems. This indicates that they are under powerful supraspinal control (red arrows in Fig. 1). The inhibitory interneurons are hypothesized to be located in the upper lumbar segments for the lower extremities (Fig. 1).

\section{Human studies}

Blumberg and Wallin [4] have shown that painful intraneural electrical microstimulation in the superficial peroneal nerve at the ankle, at a strength that excites thinly myelinated (A $\delta$ ) nociceptive afferents, elicits reflex dilation (an increase of blood flow measured with laser-Doppler flowmetry) in skin 
areas adjacent to, as well as in, the territory of the stimulated nerve. In addition to causing vasodilation ipsilaterally, this stimulus also evokes a lesser vasodilator response in the corresponding skin area of the contralateral limb. The vasodilation in the ipsi- and contralateral skin is abolished by local anesthesia of the stimulated nerve proximal to the stimulation site. Finally, the dilation is enhanced by body cooling (i.e., when the activity in cutaneous vasoconstrictor neurons is high) arguing that the reflex vasodilation is produced by the decrease of activity in CVC neurons and not by activation of cutaneous vasodilator neurons. Thus, this reflex in human beings appears very similar to the inhibitory reflex in CVC neurons elicited by cutaneous noxious stimuli in anesthetized cats and rats. Whether this inhibitory reflex in humans is spinal is yet to be determined, e.g. in experimental studies on patients with chronic spinal cord injury.

\section{Clinical implications}

The potential clinical implications of the Lovén reflex are considerable. How do these putative spinal nociceptive inhibitory vasoconstrictor reflexes behave under physiological and pathophysiological conditions, i.e. under chronic activation of the nociceptive system (e.g., during chronic inflammation or chronic nerve injury)? These implications are expressed in five hypotheses:

1. The inhibitory spinal reflex systems are switched on during the injury of peripheral tissues, promoting healing. Thus, inflammation of peripheral tissues sensitizes nociceptors; the inhibitory reflex in the vasoconstrictor pathway to the inflamed tissue is activated and the blood flows through the tissue increases.

2. The vasodilatation observed in the innervation territory of a partially injured nerve, and in the innervation territory of neighboring nerves, is thought to be due to lesion of sympathetic vasoconstrictor axons. However, based on our experimental findings, spinal inhibition of activity in preganglionic vasoconstrictor neurons may also be involved. This mechanism may operate in patients with complex regional pain syndrome (CRPS) in the acute phase [12].

3. The inhibitory spinal systems may change plastically during chronic tissue or nerve inflammation and injury leading to a decrease in functioning of these spinal inhibitory systems and to the development of positive feedback systems. These changes may occur in patients with CRPS in the chronic phase $[11,12]$.

4. The inhibitory spinal systems are involved in autonomic responses (e.g., increased blood flow) in specific regions in patients suffering from deep somatic tissue injury [11].
5. The inhibitory spinal systems connected to deep somatic tissues are activated during manual interventions at the paraspinal deep tissues in patients with functional diseases involving deep somatic tissues or viscera. The manual interventions activate deep somatic small diameter myelinated and unmyelinated high and low-threshold afferents. This afferent activation leads to an increase of blood flow through the deep somatic tissues mediated by the inhibitory reflex in vasoconstrictor neurons and to the relief of pain furthering the cure of functional diseases [14].

Lovén also contributed with discoveries in the fields of histology (taste buds, gastrointestinal lymphoid system), and the physiology of muscular contraction, but it is the description of this reflex evidencing a close integration between nociceptive and vasoconstrictor systems at the spinal cord level that has the most immediate clinical applications for patients with autonomic disorders, such as CRPS [17] and spinal cord injury.

Funding German Research Foundation.

\section{Compliance with ethical standards}

Conflict of interest The author declares that he has no conflict of interest.

\section{References}

1. Bard P (1968) Regulation of the systemic circulation. In: Mountcastle VB (ed) Medical physiology Vol. I, 12th edition. The C.V. Mosby Company, p 194

2. Bayliss WM (1908) On reciprocal innervation in vaso-motor reflexes and the action of strychnine and of chloroform thereon. Proc Roy Soc B 80:339-375

3. Bell GH, Davidson JN, Scarborough H (1950) Textbook of Physiology and Biochemistry, 6th edn. E. \& S. Livingstone LTD, London, p 520

4. Blumberg H, Wallin BG (1987) Direct evidence of neurally mediated vasodilatation in hairy skin of the human foot. J Physiol 382:105-121

5. Detweiler DK (1979) Control mechanisms of the circulatory system. In: Brobeck JR (ed) Best and Taylor's physiological basis of medical practice, 10th edn. The Williams \& Wilkins Company, Baltimore, pp 3-178

6. Hamilton W (1950) Circulation through special regions. In: Fulton J (ed) A textbook of physiology, 16th edn. WB Saunders Company, London, pp 760-765

7. Horeyseck G, Jänig W (1974) Reflexes in postganglionic fibres within skin and muscle nerves after noxious stimulation of skin. Exp Brain Res 20:125-134

8. Horeyseck G, Jänig W (1974) Reflex activity in postganglionic fibres within skin and muscle nerves elicited by somatic stimuli in chronic spinal cats. Exp Brain Res 21:155-168

9. Jänig W (1985) Organization of the lumbar sympathetic outflow to skeletal muscle and skin of the cat hindlimb and tail. Rev Physiol Biochem Pharmacol 102:119-213 
10. Jänig W (2006) The integrative action of the autonomic nervous system. Neurobiology of homeostasis. Cambridge University Press, Cambridge

11. Jänig W (2020) Sympathetic nervous system and pain. In: Pogatzki-Zahn E, Schaible H-G (eds) The senses: a comprehensive reference, vol 5. Elsevier, pp 349-378

12. Jänig W, Baron R (2003) Complex regional pain syndrome: mystery explained? Lancet Neurol 2:687-697

13. Jänig W, Spilok N (1978) Functional organization of the sympathetic innervation supplying the hairless skin of the hindpaws in chronic spinal cats. Pflügers Arch 377:25-31

14. King HH, Jänig W, Patterson MM (eds) (2011) The science and clinical application of manual therapy. Churchill Livingstone Elsevier, Edinburgh
15. Kirillova-Woytke I, Baron R, Jänig W (2014) Reflex inhibition of cutaneous and muscle vasoconstrictor neurons during stimulation of cutaneous and muscle nociceptors. J Neurophysiol 111:1833-1845

16. Lovén C (1866) Über die Erweiterung von Arterien in Folge einer Nervenerregung [On the vasodilation of arteries as a consequence of nerve stimulation]. Ber Verh königl -sächs Ges Wiss: Math -Phys Classe 18:85-110

17. Knudsen LF, Terkelsen AJ, Drummond PD, Birklein F (2019) Complex regional pain syndrome: a focus on the autonomic nervous system. Clin Auton Res 29:457-467 